\title{
Are men well served by family planning programs?
}

\author{
Karen Hardee ${ }^{1 *}$ (D) Melanie Croce-Galis ${ }^{2}$ and Jill Gay ${ }^{2}$
}

\begin{abstract}
Although the range of contraceptives includes methods for men, namely condoms, vasectomy and withdrawal that men use directly, and the Standard Days Method (SDM) that requires their participation, family planning programming has primarily focused on women. What is known about reaching men as contraceptive users? This paper draws from a review of 47 interventions that reached men and proposes 10 key considerations for strengthening programming for men as contraceptive users. A review of programming shows that men and boys are not particularly well served by programs. Most programs operate from the perspective that women are contraceptive users and that men should support their partners, with insufficient attention to reaching men as contraceptive users in their own right. The notion that family planning is women's business only is outdated. There is sufficient evidence demonstrating men's desire for information and services, as well as men's positive response to existing programming to warrant further programming for men as FP users. The key considerations focus on getting information and services where men and boys need it; addressing gender norms that affect men's attitudes and use while respecting women's autonomy; reaching adolescent boys; including men as users in policies and guidelines; scaling up successful programming; filling gaps with implementation research and monitoring \& evaluation; and creating more contraceptive options for men.
\end{abstract}

Keywords: Family planning, Men, Male engagement, Contraceptive use, Male contraceptive users

\section{Plain English summary}

Although the range of contraceptives includes methods for men, namely condoms, vasectomy and withdrawal that men use directly, and the Standard Days Method (SDM) that requires their participation, family planning programming has primarily focused on women. What is known about reaching men as contraceptive users? This paper draws from a review of 47 interventions that reached men that are grouped under five strategies: 1 ) Clinic Provision of Information and Services for Men; 2) Outreach with Male Motivators and Peer Educators/ Mentors; 3) Community Engagement; 4) Communications Programs; and 5) Comprehensive Sexuality Education. Based on analysis of these interventions and interviews with experts working on men and family planning, this paper proposes 10 key considerations for strengthening programming for men as contraceptive

\footnotetext{
* Correspondence: KHardee@popcouncil.org

${ }^{1}$ Population Council, 4301 Connecticut Ave NW, Ste. 280, Washington, DC 20008, USA

Full list of author information is available at the end of the article
}

users. A review of programming shows that men and boys are not particularly well served by programs. Most programs operate from the perspective that women are contraceptive users and that men should support their partners, with insufficient attention to reaching men as contraceptive users in their own right. The notion that family planning is women's business only is outdated. There is sufficient evidence demonstrating men's desire for information and services, as well as men's positive response to existing programming to warrant further programming for men as FP users. The 10 key considerations include: Provide information and services to men and boys where and when they need it; Address gender norms that affect men's use of contraceptive methods; Meet men's needs while respecting women's autonomy; Improve couple and community communication; Link men's contraceptive use with their desire to support their families; Teach adolescent boys about pregnancy prevention and healthy sexual relationships; Develop national policies and guidelines that include men as family planning users; Scale up programs for men; Fill the gaps 
through monitoring, evaluation, and implementation science; and Create more contraceptive options for men.

\section{Background}

Reproduction involves both women and men, and although the range of contraceptives includes methods for men, namely condoms, vasectomy and withdrawal that men use directly, and the Standard Days Method (SDM) that requires their participation, family planning programming has primarily focused on women. FP2020's goal explicitly identifies reaching an additional 120 million women and girls with family planning. Attention to gender at the 1994 International Conference on Population and Development (ICPD) in Cairo resulted in a renewed call to involve men more actively in reproductive health $[1,2]$. The framing of ICPD emphasized men as partners to support the autonomous decisions of women, with less regard for men's reproductive health and rights [3]. More recent efforts to expand the vision for constructive male engagement in family planning and reproductive health are evolving from encouraging men to be supportive partners of women's reproductive health decisions to also being change agents in families and communities, as well as meeting thir own reproductive health needs [4].

While engaging men improves reproductive health and gender outcomes [2,5-7], most evidence relates to men as partners. Less is known about reaching men as clients of family planning services. Use of male and male cooperation methods has remained steady over the past few decades at around one-quarter of contraceptive users worldwide, with current regional and country variation in use of the various methods [8]. This paper reviews current programs and evidence, including those that address gender norms that affect men's use of contraceptive methods, and proposes key considerations to strengthen programs for men as family planning users. The analysis takes a broad view of programming to include policies that create an enabling environment, services and behavior change interventions to address norms and demand creation.

\section{Methods}

This paper is based on evidence from published and grey literature documentation of interventions that included some focus on men as users of contraception in lowand middle-income countries, augmented with interviews with 36 representatives from institutions involved in relevant programming and research [9]. The four methods of male condom, vasectomy, withdrawal and the Standard Days Method, or SDM are included in the analysis.

The literature review included a search strategy for articles and reports from 2010 to 2015, and included selected programming from years prior to 2010 if one or more of these male contraceptive methods was included. To identify current programming that has not made its way into the published literature, relevant abstracts from the January 2016 International Conference on Family Planning were also reviewed. From 2,254 de-duplicated references found through PubMed and POPLINE, the majority of the 500 articles, reports and abstracts reviewed focused on men as supporters of women's contraceptive use; 47 that included some focus on men as users of contraception were included in the analysis. The information in the interviews was used to ensure that all essential programming was covered, including ongoing programming that may not yet be evaluated as well as used to get expert opinions on the state of programming for men as contraceptive users.

\section{Results}

Programs for men as contraceptive users

Men have been reached as users of contraception through a range of programming that spans creating demand and expanding supply, in addition to addressing the enabling environment. Programming for men generally falls under the following five broad strategies that are designed to increase demand for and improve the supply of contraceptive information and services. The strategies include: 1) Clinic Provision of Information and Services for Men; 2) Outreach with Male Motivators and Peer Educators/Mentors; 3) Community Engagement; 4) Communications Programs; and 5) Comprehensive Sexuality Education. Two of the strategies, namely communication programs and community engagement, include substrategies. Table 1 shows the strategies, the number of interventions found under each strategy, the countries of implementation and the categorization of the strategy as proven, promising or emerging based on the strength of evidence for each strategy adapted from the Family Planning High Impact Practices initiative [10]. Evidence for the strategies ranged from randomized control trails to service statistics. The 47 interventions, their outcomes and the strength of evidence are described in more detail in Hardee et al. [9]. The interventions were carried out in 27 countries spanning Africa, Asia, Latin America and the Caribbean, and the Balkans.

Not all interventions specifically measured use of male methods, nor disaggregated data by sex, however, it is possible to draw some conclusions about the effect of programming on male use of contraception. Interventions sought to improve men's attitudes towards family planning, their knowledge of specific methods of contraception, and their use of family planning generally or 


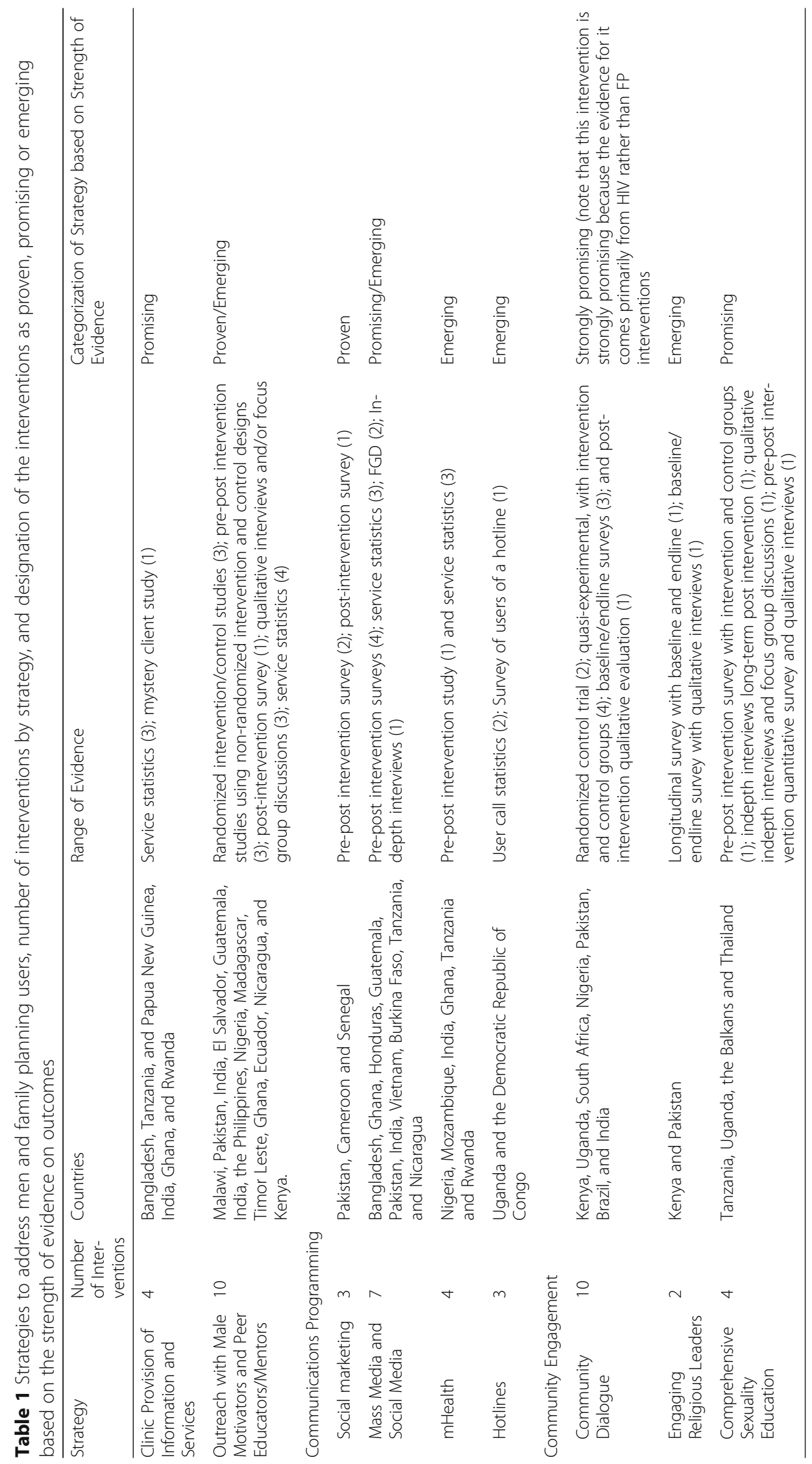


male methods specifically. Furthermore, most of the interventions sought to address gender norms around family planning use - mostly to promote male support for their partner's use, but also some to promote male use of methods. The interventions found, as other cross sectional studies show, that men want information on family planning and the notion that family planning is women's business only is no longer true. When male methods, notably condoms, vasectomy and SDM, were made available through interventions, uptake generally increased. Finally, a number of the interventions had positive outcomes related to promoting more equitable gender norms related to family planning and increasing couple communication on fertility and contraceptive use.

\section{Key considerations in programming for men as contraceptive users}

The review of programming, in addition to the broader literature on gender and family planning and interviews with experts, identified a number of issues that are important to consider in programming for men as family planning users (Table 2).

\section{Provide contraceptive information and services to men and boys where and when they need it}

Reproductive health services are largely seen as spaces for women, with male norms of masculinity often challenged by men's accessing reproductive health services [11-13]. Most family planning services are perceived as not welcoming to men as either partners or clients in and of themselves, with a lack of health infrastructure targeting men, including policies, services and hours of services $[14,15]$. Furthermore, the capacity of health workers to counsel men on contraception is lacking [16].

Programs could make better use of existing facilities by extending hours, or allocating time for men and couples [17]. Providing family planning through pharmacies and drug shops is a promising Family Planning High Impact Practice [18]. These venues may be preferred by

Table 210 Key considerations in programming for men as family planning users

- Provide information and services to men and boys where and when they need it

- Address gender norms that affect men's use of contraceptive methods

- Improve couple and community communication

- Meet men's needs while respecting women's autonomy

- Link men's family planning use with their desire to support their families

- Teach adolescent boys about pregnancy prevention and healthy sexual relationships

- Develop national policies and guidelines that include men as family planning users

- Scale up programs for men

- Fill the gaps through monitoring, evaluation, and implementation science

- Create more contraceptive options for men men who are reluctant to attend health facilities, particularly if they have to travel long distances [19].

There is a large gap in men and adolescent boys' access to information and services, leading to a disparity between male and female knowledge of and access to contraceptives. As Piet-Pelon et al. [20] reflected “.... How is it that we woke up so recently to the fact that men are likely to be just as out of the loop on correct information as their partners?.... How had we expected them to participate when we neither shared information nor provided them with accessible services?" (p. 61).

Adolescent boys and men want information to inform their sexual lives, enhance their understanding of contraceptive options, and to protect themselves from HIV but have limited options on where to obtain this information. Studies show that men sometimes obtain their information from the media (including pornography sites) or from other male friends but this information may not always be accurate. Many men stress the importance of communication around sex and reproduction but do not have skills to do so [21]. Men want to know about how to combat infertility and sexual inadequacies [22] and they generally want male providers with whom they can discuss these sensitive issues [23]. Men also want guidance on how to use a condom effectively but may be embarrassed to ask. Boys, too, were found to want information on sex, impotency, infertility, and erectile dysfunction just like married men [24]. In some countries, service providers are unwilling to provide contraceptive information or methods to unmarried adolescent boys [24].

Further, parents in many countries focus on adolescent girls and pregnancy, as "when girls become pregnant the responsibility rests mostly on their parents and not the boys" [25]. Health care workers may share this view, and therefore do little to provide information or contraception to adolescent boys [25]. Yet young men have reported a strong desire for information about sex-related matters, both from their families and the health system.

Hotlines are demonstrating promise as platforms to reach men with information about contraceptives and available services, in addition to other health information men need. In the Democratic Republic of Congo (DRC), evaluation of use of a family planning hotline Ligne Verte - found that although women were the primary target of the hotline, men represented $80 \%$ of the 20,000 calls per year, with men asking for information about contraception and where to obtain it [26]. The vast majority (94\%) of calls to a hotline in India were from males, who asked for a range of information, including about erectile disfunction, early ejaculation, masturbation, HIV/AIDs, anxiety about penis length, pre-marriage anxiety and guidance; infertility, nocturnal emissions, gender orientation; contraception, STI, and 
on consummation of marriage, among other topics [27]. Similarly, mHealth programming is increasing, with good participation from men [28-31].

Integrating contraceptive information in other development projects can take advantage of reaching men where they work. Interventions in El Salvador and Honduras successfully increased men's knowledge and reported family planning use by incorporating information and referrals into agricultural work through volunteers talking to men in the fields while they were working [32].

\section{Address gender norms that can limit or promote men's participation in contraceptive use}

Most programming is based on the perception that gender norms value masculinities that include bragging about sexual encounters, having frequent sex and multiple partners and leaving the responsibility for unintended pregnancies to women [33]. This view of gender norms surrounding sexuality, reproductive health and family planning reinforce the focus on female use of contraception. Gender inequitable norms can diminish the likelihood of discussions of contraception and joint decision-making on reproductive health [34]. Where gender inequality is strong, men are less likely to use a condom [35].

Masculine ideals may also involve showing respect for and protecting their female partners. Both views of masculinity can affect family planning use by women and men $[36,37]$. Where men and boys have been exposed to gender equality programming, they are more likely to report increased contraceptive use, including condom use.

Equitable gender norms can positively impact use of vasectomy and that countries with current high rates of vasectomy are also ones that are more gender equitable (Personal communication with F. Verani, October 9, 2015). In Costa Rica, men who held more gender equitable (less "machista") views pursued getting a vasectomy as part of their quest for emotional commitment to their wives and to the well-being of their wives. Men who got vasectomies saw themselves as being responsible for averting unintended pregnancies [38]. Vasectomies have increased in Costa Rica 76\% from 2000 to 2003 and another 70\% between 2003 and 2006, with low fertility linked to being a "modern" man. The method became so popular that there was a reported 2-years wait to get a vasectomy in a social security hospital in 2009.

Data from 58 Demographic and Health Survey (DHS) men's surveys in 18 countries showed that men generally consider family planning their business as well as women's [39]. In surveys in 12 countries, men were asked whether they agreed with the statement, "contraception is a woman's business and a man should not have to worry about it." In all of the 12 countries included in the analysis (ten in Africa and two in Asia), over half of the men disagreed with the statement, and in six of the 12 countries, over $70 \%$ of the men disagreed.

Men's views of gender equality and their roles in contraceptive decisionmaking are not monolithic. Severy [40] notes the importance of understanding the variation in power dynamics, both across and within cultures and relationships. Ethnographic work in Egypt illustrates that men do express concern for the health and wellbeing of their wives, at the same time they express their authority and power [41]. Indeed, many men considered their wives as partners, although they also recognized their socially mandated role as providers and felt a strong sense of responsibility for their families. Further, data from South Africa, Kenya and Uganda (1999-2000) indicated that men were no more likely than women to be against family planning [42].

Understanding the views of policymakers and program managers on men's use of contraception is also important since that has implications for policy development and program implementation. For example, in Benin, Diakite [43] notes that one barrier to male engagement in family planning, including as users, is "lack of interest and appreciation for men in government FP initiatives." Writing about Indonesia and citing statistics on use of condoms, vasectomy and withdrawal, which ranged from $3.1 \%$ in 1987 to $2.8 \%$ in 2003 , Hull [44] claims that Indonesia missed an opportunity to promote men's use of contraception. He explained that:

"Leaders in the community and the family planning program were remarkably conservative about the idea of promoting male methods. Increasingly, they questioned the efficacy of condoms and the acceptability of vasectomy, opting to ignore the fact that the public was quite interested in trying male methods.... Indonesia saw a steady decline in reported condom use for family planning (and for HIV prevention) and the failure of relatively inexpensive male sterilization to reach even one-ninth of the number of female sterilizations" P. 245.

\section{Improve couple and community communication}

Couple communication is important for improving contraceptive use and gender equity and is a component of many interventions to promote male engagement $[45,46]$. When couples have discussed family planning, contraceptive use tends to go up, with recent evidence from Kenya [47]; Ethiopia [48-50]; Nepal [51]; Bangladesh [52] and Pakistan [53, 54]. An analysis of DHS survey data from Bangladesh, for example, found that discussions between husband and 
wife on family planning was the single most significant effect on both current contraceptive use and modern method preference [52]. Promoting couple communication should include encouraging partners to discuss use of contraception by either partner.

Promoting dialogues among community members can also increase gender equality and thus affect men's and women's sexual and reproductive health, including contraception. Related programing examples include the GREAT Project in Uganda [55], Stepping Stones in South Africa [56, 57], SASA! in Uganda [58, 59], CARE's Results Initiative in Kenya [60], and Program H in Brazil $[61,62]$. These program examples show that when informed by the need to address inequitable gender norms, increasing community dialogues and couple communication about power dynamics, the need for gender equality and the importance of contraception may lead to a number of positive public health and gender equity outcomes.

Some have noted the need to ensure that couples communication interventions take into account unequal power in relationships [63] and Green ME, Barker G, Olukoya A, Pawlak P, Contreras JM and Heilman B: What happens when we engage men?, unpublished. CARE's Family Planning Results Initiative, implemented in western Kenya from 2009 to 2012, found that while both women and men described a shift towards gender equitable roles, "many couples still reported that men were the primary decision-makers within relationships" (P. 7) [60]. While women in the project intervention described many benefits of partner use of and support for family planning, for those women who did face opposition from their partners, the women "specifically discussed the critical importance of their ability to independently access family planning" (P. 40) [60].

Shifting power dynamics in couple communication can involve incrementally subtle shifts. In Malawi, an intervention using male motivators evaluated through a randomized design with 400 men divided between the intervention and control groups, found that contraceptive use increased significantly in the intervention group (78\%) compared to the control group (59\%), with men's discussions with their wives as a significant factor in family planning uptake [64]. Of the men who reported family planning uptake, 56\% reported using condoms. 1 year following the intervention, 30 female partners were also interviewed. As a result of the male motivator program, all men noted the importance of increased information and knowledge in contributing to spousal communication and family planning use, with the majority of men and women reporting more frequent and easier communication between spouses, particularly in relationship to family planning [64]. The women also appreciated the male motivator program for reaching their husbands and addressing their opposition to family planning, making it easier for couples to discuss family planning.

The study in Malawi analyzed the gendered patterns of decisionmaking, finding that few participants said that it was the man's role to decide on family planning. Yet, the findings also showed that a majority of women and men described the decision to use family planning as being made by men, while the decision of what method to use was more mixed between women, men and couples together. While this appears to strengthen men's domination of women, the reality in Malawi was more subtle. The authors concluded:

"Despite that many women still played a passive role in communication, that they are consulted at all represents a shift and was described as such by the women. This is also supported by the increased respect women felt they received from their partners and by perceived improvements in their relationships as a result of improved communication. Although the ideal of equal decision-making may not yet be a reality, this represents a positive change in that direction" (P. 816) [64].

\section{Meet men's needs while respecting women's autonomy}

Although engaging men in family planning, as users and supportive partners, is gaining acceptance, there is concern about effects of male engagement on women's autonomy and the fundamental human right for women to control "their own sexuality, their bodies and their health" (P. 10) [65]. Some women may not want men to be responsible for contraception, fearing that a mistake or omission by their partner may lead to an unintended pregnancy [22]. It is critical, then, to learn from early mistakes made in programming to promote male engagement that appealed to stereotypic gender norms [66, 67], and to make sure that interventions to encourage male contraceptive use do not disempower women and reinforce gender inequalities [34]. The United Nations Population Fund (UNFPA), which supports husband's schools to reach men and influence them to support women's reproductive health, reports that couple communication has increased and men have a greater understanding of the importance of the health and wellbeing of their wives and children [68]. However, an evaluation of the husbands' schools by the Institute for Reproductive Health will help show if the approach promotes gender equity or reinforces male dominance.

Men should be able to exercise their reproductive right to use contraception, but they should not be able to deny their partner's right to use family planning. While highlighting the benefits of involving both men and women in contraception, women must retain the ability to choose to use contraception and to access services alone (Stern, [69]; Tao et al. [70]). 
Link men's family planning use with their desire to support their families

More attention has recently been focused on men as engaged fathers [22]. Whether an adolescent boy or a man wants to become a father is an important question with potential consequences not just for the women or adolescent girl who becomes pregnant but also for the man or adolescent boy. Men's attitudes have been changing and men want to be involved in decisions about having or not having children [71]. A 2014 study in Pakistan found that one of the main motivators behind a trend of wanting smaller families is economic stress and pressure men feel about being the main income earners for their family [72]. Another study of married men in Pakistan found that the perception that a responsible, caring husband uses family planning to improve the standard of living of his family and to protect his wife's health made men 1.5 times more likely to intend to use a condom [73].

In Jamaica, the Women's Center Foundation has a longstanding and successful program to help school-age girls who get pregnant stay in school and delay having more children [74]. A study in 2002 of the "baby fathers" of girls who had been in the program between 1990 and 1994 [75], found that the boys considered themselves better fathers than their fathers had been but "many felt that a separate program for men could help them communicate with their sons about reproductive health, sexuality, and personal development" (P. 20) [2].

\section{Teach adolescent boys about pregnancy prevention and healthy sexual relationships}

Sexuality education that is gender transformative is more effective in pregnancy prevention than sexuality education that does not challenge gender norms [76]. Comprehensive sexuality education therefore "must talk about parenthood and make the link between sexuality and fatherhood more explicit" (P. 139) [21]. Many adolescent pregnancy prevention programs reinforce gender inequality by reinforcing the notion that girls are the only ones responsible for preventing an unintended pregnancy [12]. Almost nothing is known about the impact of early, unintended and unwanted pregnancy on the lives of adolescent boys [77]. Some experts have recommended the need for age appropriate educational programs on sexual and reproductive health, including how boys can responsibly prevent unintended pregnancy [16] and Todesco M and Gay J: Guidance for the education sector on preventing unintended adolescent pregnancies, forthcoming from UNESCO.

\section{Develop national policies and guidelines that include men as family planning users}

Ensuring that constructive male engagement, including men as users, is included in national policies and guidelines is nascent $[4,78]$. A review of public policies to promote gender equality in Mexico, South Africa, Chile, India and Brazil found gaps in health policies, among other sectoral policies, and noted the need for policies that both engage men in supporting their partners in contraceptive use but also that promote men's use of male methods [79].

Some countries have successfully integrated policies regarding men's involvement in sexual and reproductive health. Cambodia was among the first countries to do so in 2003. These guidelines, including reaching men as family planning users in addition to being supportive partners, were integrated into the 2006-2010 National Strategic Framework for Reproductive and Sexual Health in Cambodia [80].

A number of countries have developed Family Planning Costed Implementation Plans (CIPs) where family planning activities are planned and costed with a view to scaling up programming. Reviewing a country's CIP for male inclusion is one concrete way to ensure adequate focus on men in family planning programming. Analysis of five CIPs from African countries (Ghana, Malawi, Uganda, Senegal, and Tanzania) suggests that most programming for men focuses on increasing their support for their partners' use of contraception with little attention on increasing men'a own use of contraception [81-85].

\section{Scale up programs for men}

Programming for men as contraceptive users is scant, although growing, and even interventions to engage men in family planning as partners have remained small scale and short term [69, 86-88]. There are, however, some approaches that have demonstrated success in constructive male engagement, including as contraceptive users, and could be scaled up at regional and national levels. Multidimensional programs have the potential to show even greater impact if carried out with a wider approach over a longer term.

Communications programming in Bangladesh, Ghana, Honduras, Guatemala, Pakistan, India, Vietnam, Burkina Faso, Tanzania, and Nicaragua show that mass media can create national conversations that address the social and cultural barriers to men's contraceptive use. Social media is a rising force that can be harnessed to connect men to information and services as seen in the use of Facebook by WINGS in Guatemala to publicise the availability of vasectomy [89]. Social marketing can challenge social norms and help overcome barriers to acceptability of contraceptive use. Use of male motivators and other trained male peers has repeatedly demonstrated success on a small scale. This programming could be more effective on a large scale if it were linked with other strategies, such as comprehensive sexuality education that includes information on men and boys' 
contraceptive needs; provider training and information and service provision for men; and gender-responsive programming that improves couple communication and joint decisionmaking. The FALAH Project, implemented between 2008 and 2012 in Pakistan shows that programming for men can reach millions of men. That project spanned 20 districts across four provinces and reached more than 9 million women and men [54]. The FALAH Project engaged men through multiple strategies including male motivators and peers, mass media, theatre performances, men's groups, and religious leaders. An mHealth solution in India that supports fertility awareness and use of SDM (CycleTel Family Advice and CycleTel Humsafer) has been developed by the Institute for Reproductive Health in partnership with a private sector organization [30]. Its ongoing implementation will provide information on managing a commercial partnership as a pathway to scale and sustainability.

An ongoing challenge will be ensuring enough supply of vasectomy services and condoms to meet the growing demand that would be generated through scaled up programming for men. Experience in KwaZulu Natal in Western Cape, South Africa, shows that with political will, this challenge could be met: After a significant drop in condom use in South Africa at last sex between 2008 and 2012 [90], KwaZulu Natal officials distributed 58.9 condoms per adult male in 2014, up dramatically from 8.2 condoms per male in 2010 [90]. While this effort to increase condom use was based on HIV prevention rather than for increasing uptake of male contraceptive methods, it shows how political will can dramatically scale up condom distribution, facilitating greater availability for use.

\section{Fill the gaps through monitoring, evaluation, and implementation science}

Review of programming for men as family planning users found few robust evaluations of programs to engage men, let alone programs directed at men as contraceptive users. Many of the male-focused programs have positioned men as partners and supporters of women's contraceptive use and thus it is difficult to separate those interventions from those aimed at increasing male contraceptive use and engaging men in their own sexual and reproductive health. Furthermore, not all programs report findings disaggregated by sex, and by contraceptive method, making it difficult to determine the effect of programming on male use of methods. Few studies ask men directly about their experiences with contraception, but instead are most likely to ask female partners what changes have occurred in male partners' attitudes and practices based on interventions with women [23, 91-93].
If men are continually viewed as obstacles or accessories to women's health, it will be impossible to meet men's needs. A greater understanding of men's contraceptive and reproductive health needs begins first with the recognition of their rights to information and services for them. More systematic data collection on men's fertility and relationships could greatly enhance information and service provision for men. Beyond that, there is a need to better understand the process of change for men, rather than just providing outcomes [69]. There is little literature on factors to increase uptake or barriers that prevent men from using contraception from the viewpoint of men themselves [34]. Critical research is missing on what are effective programs to increase responsibility by adolescent boys, prior to sexual activity, to prevent unintended pregnancy through male or female contraceptive use, as well as to ensure dialogue on pregnancy prevention, and that the sexual act is consensual.

Regional and country contexts are important in developing this research.

Funding for research and evaluation remains an ongoing challenge. Some efforts would benefit from rigorous evaluation but do not have funds to carry out endline surveys or evaluate that data. For example, there is a current effort to increase contraceptive use among both boys and girls in Togo using the "It's All One" curriculum, but evaluation of genderrelated and contraceptive uptake outcomes is needed (Personal communication with M. Toliver, October 23, 2015). The curriculum Gender Matters, or Gen.M, developed in the United States, [94] promotes gender equality and teaches boys about their roles and responsibilities in preventing unintended pregnancies, including that they can use contraception, can be adapted for use in developing country settings but such adaptations would need to be evaluated (Personal communication with J. DeAtley, December 2, 2015).

Programming to promote existing male methods could benefit from further evaluation. For example, though it does not have recurrent costs, SDM requires counseling and provider training. Further evaluation of SDM programming could lead to a greater understanding of how to better position the method for increased use. Condom programming would benefit from additional research on how to sustain condom use after marriage, especially as a dual strategy. Vasectomy programming may benefit from further evaluation of successful interventions that have dispelled myths and fears of loss of potency for men and that have changed community norms around acceptance of male sterilization. While programs do not promote withdrawal, research could help position it at least as a method couples could use if needed in the absence of another method. 


\section{Create more contraceptive options for men}

Review of programming for men reinforces that men need additional contraceptive options beyond the methods currently available to them. There is sizable demand for a novel male contraceptive option, particularly for reversible contraception [34, 95]. In a survey of more than 9,000 men ages 18-59 across nine countries, $28.5-71.4 \%$ of men of various nationalities expressed a willingness to use a hormonal male contraceptive [96]. Dorman and Bishai [97] note that "even assuming that only $25 \%$ of men who indicated they would 'definitely' or 'probably' use male contraception in the Heinemann et al. survey, the estimated number of potential users ages 15-64 years in those nine countries alone is close to 44 million" (p. 5) [98]. Surveys of women's acceptability of a male pill in Edinburgh, Cape Town, Shanghai and Hong Kong have shown that while women may not trust men in general, they were more trusting when it came to their own partner [95, 98]. A study in south-west Nigeria of 329 men ages 18 - 60 years who were married or cohabiting and had at least one child found that most men would be willing to accept reversible male contraception [99]. Shand found in field interviews in Malawi that men stated that the best family planning methods were for women and therefore, men do not use contraception (Personal communication with T. Shand, October 15, 2015).

Work to develop additional male methods of contraception has been going on for decades with a focus on hormonal and non-hormonal approaches. Creation of novel hormonal methods for men has stalled, however. Many of the attempted hormonal formulations created for men have had a number of intolerable side effects [97]. A recent trial of a hormonal contraceptive injection for men, which was found to be nearly as effective as the pill for women, was halted early due to side effects [100]. In spite of the side effects, three-quarters of the men in the trial said they would be willing to continue to use the method if it were available [101]. Reformulation of the hormones may decrease the side effects. Currently, some promising new non-hormonal methods for men are under development, including Vasalgel, the RISUG method, and Gendarussa [102].

Funding is a challenge for male contraceptive development. Pharmaceutical companies are not currently investing in new contraceptive development, leaving smaller efforts by non-profit organizations and foundations to fill the gaps. With adequate funding, there could be a new male contraceptive on the market within a decade. Without adequate funding, efforts may take 20 or more years to bear fruit.

\section{Conclusion}

Review of programming for men as family planning users shows that currently, men and boys are not particularly well served by programs. Most programs operate from the perspective that women are contraceptive users and that men should support their partners, with insufficient attention to reaching men as family planning users in their own right. At the same time, the review highlighted that there is sufficient evidence demonstrating men's desire for information and services, as well as men's positive response to existing programming to warrant further programming for men and boys in family planning and contraceptive services. Review of programming shows strategies for reaching men with evidence ranging from proven (social marketing; and outreach with male motivators and peer educators/menotors), to promising (clinic provision of information and services; mass media; promoting community dialogue and comprehensive sexuality education), and emerging (social media; mHealth; hotlines; and engaging religious leaders). These strategies, along with recommendations for further implementation science highlights the need to strengthen programming to engage men as family planning users in addition to efforts to address genderbased norms and behavior that hinder contraceptive use. This paper also articulates key considerations that should be taken into account to orient programming to reach men and boys with the information and services they need to be contraceptive users. While programming for men should not compromise women's autonomy, it should also not be implemented with the assumption that contraceptive use is only for women.

Scaling up successful programming and ensuring that the key considerations for programming are intregated into interventions for men, and continuing to undertake robust implementation research and valuation, will increase men's knowledge and use of family planning services, reduce barriers, increase gender equality and improve the health and well being of men and women, boys and girls worldwide.

\section{Abbreviations \\ CIP: Costed Implementation Plan; DHS: Demographic and health surveys; FALAH: Family advancement for life and health project; GREAT: Gender roles, equality, and transformation project; ICPD: International Conference on \\ Population and Development; SDM: Standard Days Method; UNFPA: United Nations Population Fund}

\section{Acknowledgments}

NA

\section{Funding}

Support for this manuscript comes from the Evidence Project, with funding from USAID under cooperative agreement no. AID-OAA-A-13-00087.

\section{Availability of data and materials}

NA. 


\section{Authors' contributions}

$\mathrm{KH}$ contributed to the analysis and categorization of the interventions and led the writing of the manuscript. MCG contributed to the analysis of the interventions and writing of the manuscript. JG reviewed the literature on the interventions, contributed to the analysis and to writing the manuscript. All authors read and approved the final manuscript.

\section{Competing interests}

The authors declare that they have no competing interests.

\section{Consent for publication}

NA.

\section{Ethics approval and consent to participate} NA.

\section{Author details}

'Population Council, 4301 Connecticut Ave NW, Ste. 280, Washington, DC 20008, USA. ${ }^{2}$ What Works Association, 54 Mills St, Morristown, New Jersey 07960, USA.

Received: 26 August 2016 Accepted: 4 January 2017 Published online: 23 January 2017

\section{References}

1. Ringheim K. Revising the downward trend in men's share of contraceptive use. Reprod Health Matter. 1999;7(9):83-96.

2. Boender C, Santana D, Santillán D, Hardee K, Greene ME, Schuler S. The 'so what?' report: A look at whether integrating a gender focus into programs makes a difference to outcomes. Washington: Interagency Gender Working Group; 2004.

3. Wentzell EA, Inhorn MC. Reconceiving masculinity and 'men as partners' for ICPD beyond 2014: insights from a Mexican HPV study. Glob Public Health. 2014;9(6):691-705.

4. Interagency Gender Working Group (IGWG). Engaging men for gender equality and improved reproductive health. Washington: IGWG; 2009.

5. Rottach E, Schuler SR, Hardee K. Gender perspectives improve reproductive health outcomes: new Eevidence. Washington: The Interagency Gender Working Group; 2009.

$6 \quad \mathrm{RH}$. From family planning to fatherhood: Analysis of fecent male involvement initiatives and scale-up potential. Washington: Institute for Reproductive Health, Georgetown University; 2013.

7 Kraft JM, Wilkins KG, Morales GJ, Widyono M. An evidence review of gender-integrated interventions in reproductive and maternal-child health. J Health Commun. 2014;19 Suppl 1:122-41.

8 Ross J and Hardee K. Trends in male contraceptive use. J Biosoc Sci. 2016; doi:10.1017/S0021932016000560.

9 Hardee K, Croce-Galis M, Gay J. Men as contraceptive users: Programs, outcomes, and recommendations. Working Paper. Washington: Population Council, The Evidence Project; 2016.

10 HIP Family Planning High Impact Practices. https://www. fphighimpactpractices.org/. Accessed 19 Dec 2016.

11 Croce-Galis M, Salazar E, Lundgren R. Male engagement in family planning: Reducing unmet need for family planning by addressing gender norms. Washington: Institute for Reproductive Health, Georgetown University; 2014.

12 Bukar M, Audu BM, Usman HA, El-Nafaty AU, Massa AA, Melah GS. Gender attitude to the empowerment of women: an independent right to contraceptive acceptance, choice and practice. J Obstet Gynaecol. 2013; 33(2):180-3

13 Jooste K, Amukugo HJ. Male involvement in reproductive health: a management perspective. J Nurs Manag. 2013;21(2):327-38.

14 Pascoe L, Herstad TM, Shand T, van den Heever L. Building male involvement in SRHR: A basic model for male involvement in sexual and reproductive health and rights. Cape Town: Sonke Gender Justice Network; 2012

15 Adelekan A, Omoregie P, and Edoni E. Male involvement in family planning: Challenges and way forward. Int J Pop Res 2014;Article416457,9p.

16 Kura S, Vince J, Crouch-Chivers P. Male involvement in sexual and reproductive health in the Mendi district, Southern Highlands province of Papua New Guinea: a descriptive study. Repro Health. 2013;10(1):1-10.
17 MenEngage, Sonke Gender Justice and Promundo. Africa regional SRHR consultation meeting report. MenEngage, Sonke Gender Justice and Promundo; 2014.

18 High-Impact Practices in Family Planning (HIP). Drug Shops and Pharmacies: Sources for family planning commodities and information. Washington: USAID; 2013.

19 Okonkwo AD, Okonkwo UP. Patent medicine vendors, community pharmacists and STI management in Abuja, Nigeria. Afr Health Sci. 2010;10(3):253-65.

20 Piet-Pelon NJ, Rob U, Khan ME. Men in Bangladesh, India and Pakistan: Reproductive health issues. India: Hindustan Publishing Corporation; 1999.

21 Rutgers WPF and Promundo. Synthesis of the formative research of MenCare + in Indonesia, South Africa, Brazil, Rwanda. Utrecht: Rutgers WPF and Promundo; 2014

22 Levtov R, Van der Gaag N, Greene M, Kaufman M, Barker G. State of the world's fathers. Washington: Promundo, Rutgers, Save the Children, Sonke Gender Justice, and the MenEngage Alliance; 2015.

23 Kamran I, Tasneem Z, Parveen T, Niazi R. Family planning through the lens of men: Readiness, preferences, and challenges. Washington: Population Council, The Evidence Project; 2015.

24 International Planned Parenthood Federation (IPPF). Gender, masculinities \& sexual health in South Asia. New Delhi: IPPF, South Asia Regional Office; 2013.

25 Kumi-Kyereme A, Awusabo-Asare K, Darteh EK. Attitudes of gatekeepers towards adolescent sexual and reproductive health in Ghana. Afr J Repro Health. 2014;18(3):142-53.

26 Kasongo G, and Makuta A. Ligne Verte: Outil d'informations sur la planification familiale en République Démocratique du Congo. Abstract at the 2016 International Conference on Family Planning. Nusa Dua, Indonesia. 2016. https://www.xcdsystem.com/icfp/program/index.cfm?pgid=289\&search= 1\&qtype=speaker\&speakerid=175590\&submit=Go. Accessed 18 Dec 2016.

27 Malde S. Addressing sexual and reproductive health needs of adolescents: Telephone helpline experience. In: Donta B, Vogelsong K, Van Look PFA, Puri $\mathrm{C}$, editors. Enhancing male partnership in sexual and reproductive health. Geneva: WHO; 2005. p. 255-64.

28 Ajidagba EB., Adenipekun A, Mapayi B, Bello, BM, and Fatusi, A. Breaking barriers of youth's access to contraceptives: The mobile phones technology approach. Abstract at the 2016 International Conference on Family Planning. Nus Dua, Indonesia. 2016. https://www.xcdsystem.com/icfp/ program/index.cfm?pgid=289\&search=1\&qtype=speaker\&speakerid= $177195 \&$ submit=Go. Accessed 18 Dec 2016

29 Feyisetan B, Benevides R, Badiani R and Mutombo N. Improving youth's sexual and reproductive health knowledge, attitudes, and self-efficacy related to contraception through short message services (SMS) education: Evidence from Mozambique. Abstract at the 2016 International Conference on Family Planning. Nusa Dua, Indonesia. 2016. https://www.xcdsystem. com/icfp/program/index.cfm?pgid=289\&search=1\&qtype $=$ speaker\&speakerid=174708\&submit=Go. Accessed 18 Dec 2016.

30 Ettinger A, Ashcroft CN, Ahmad D, Chadha C and Shelus V. "The linkages between fertility awareness and family planning uptake: Program findings of scaling mHealth services in India." Abstract at the 2016 International Conference on Family Planning. Nusa Dua, Indonesia. 2016. https://www. xcdsystem.com/icfp/program/index.cfm?pgid $=289 \&$ search $=1 \&$ qtype $=$ speaker\&speakerid=173689\&submit=Go. Accessed 18 Dec 2016.

31 Plourde $\mathrm{K}$, Vahdat $\mathrm{H}$ and L'Engle $\mathrm{K}$. Engaging audiences through FP role model story narratives delivered via mobile phone in Ghana, Tanzania and Rwanda. Abstract at the 2016 International Conference on Family Planning. Nusa Dua, Indonesia. 2016. https://www.xcdsystem.com/icfp/program/index. cfm?pgid=289\&search=1\&qtype=speaker\&speakerid=175944\&submit=Go. Accessed 18 Dec 2016

32 Lundgren R, Mendoza I, Valmana DM, Canahuati J. Strategies to involve men in reproductive health care: from farm management to family management. New York: Population Council; 1998.

33 Hoga LA, Rodolpho JR, Sato PM, Nunes MC, Borges ALV. Adult men's beliefs, values, attitudes and experiences regarding contraceptives: a systematic review of qualitative studies. J Clin Nurs. 2014;23(7-8):927-39.

34 Kabagenyi A, Jennings L, Reid A, Nalwadda G, Ntozi J, Atuyambe L. Barriers to male involvement in contraceptive uptake and reproductive health services: a qualitative study of men and women's perceptions in two rural districts in Uganda. Repro Health. 2014:11(1):21.

35 Barker G, Ricardo C, Nascimento M, Olukoya A, Santos C. Questioning gender norms with men to improve health outcomes: evidence of impact. Glob Public Health. 2010;5(5):539-53. 
36 Campo-Engelstein L. Gender norms and contraceptive trust. Albany Law J of Sci Technol. 2013;23(3):581-628.

37 Snow RC, Winter RA, Harlow SD. Gender attitudes and fertility aspirations among young men in five high fertility East African countries. Stud Fam Plann. 2013;44(1):1-24.

38 Pomales TO. Men's narratives of vasectomy: rearticulating masculinity and contraceptive responsibility in San Jose, Costa Rica. Med Anthropol Q. 2013; 27(1):23-42.

39 MacQuarrie KLD, Edmeades J, Steinhaus M, Head KS. Men and contraception: Trends in attitudes and use. DHS Analytical Studies No. 49. Rockville: ICF International; 2015.

40 Severy L. Sexual and reproductive health needs of men worldwide. In: National Institute for Reproductive Health, Indian Society for the Study of Reproduction and Fertility, and the UNDP/UNFPA/WHO/World Bank Special Program of Research, Development and Research Training in Human Reproduction, editors. Proceedings of the International Conference on Men as Partners in Sexual and Reproductive Health. November 28-December 1, 2005.

41 Ali KA. Planning the family in Egypt: New bodies, new selves. Austin: Center for Middle Eastern Studies, University of Texas at Austin; 2002.

42 Cleland J, Maharaj P. Power over reproductive decisions: Relative roles of husbands and wives in Eastern and Southern Africa. In: Donta B, Vogelsong $\mathrm{K}$, Van Look PFA, Puri C, editors. Enhancing male partnership in sexual and reproductive health. Geneva: WHO; 2005. p. 325-36.

43 Diakite M. Promoting the acceptance and willingness of men to use FP methods. In: Center for Health and Social Justice, editor. Windows to working with men and boys, Compendium of interventions and research from the $2^{\text {nd }}$ MenEngage global symposium 2014. New Delhi: Men and boys for gender justice; 2014. p. 70-1.

44 Hull T. Formative years of family planning in Indonesia. In: Robinson WC Ross JA, editors. The global family planning revolution: Three decades of population policies and programs. Washington: The World Bank; 2007.

45 Becker S. Couples and reproductive health: a review of couple studies. Stud Fam Plann. 1996;27(6):291-306.

46 Toure L. Male involvement in family planning: A review of selected program initiatives in Africa, The SARA Project. 1996.

47 Irani L, llene SS, Fotso JC. Relationship characteristics and contraceptive use among couples in urban Kenya. Int Perspect Sex Reprod Health. 2014;40(1): $11-20$.

48 Dynes M, Stephenson R, Rubardt M, Bartel D. The influence of perceptions of community norms on current contraceptive use among men and women in Ethiopia and Kenya. Health \& Place. 2012;18(4):766-73.

49 Tilahun T, Coene G, Temmerman M and Degomme O. Spousal discordance on fertility preference and its effect on contraceptive practice among married couples in Jimma zone, Ethiopia. Reprod Health. 2014;11(27).

50 Tilahun R, Coene G, Temmerman M and Degomme, O. Couple based family planning education: changes in male involvement and contraceptive use among married couples in Jimma Zone, Ethiopia. BMC Pub Health. 2015; 15(682). doi:10.1186/1742-4755-11-27.

51 Link CF. Spousal communication and contraceptive use in rural Nepal: an event history analysis. Stud Fam Plann. 2011;42(2):83-92. doi:10.1186/ s12889-015-2057-y.

52 Kamal SM, Islam MA. Contraceptive use: socioeconomic correlates and method choices in rural Bangladesh. Asia Pac J Public Health. 2010;22(4):436-50.

53 Kamran I, Arif MS, Vassos K. Concordance and discordance of couples living in a rural Pakistani village: perspectives on contraception and abortion-a qualitative study. Glob Public Health. 2011;6 Suppl 1:S38-51.

54 Ashfaq S, Sadiq M. Engaging the missing link: Evidence from FALAH for involving men in family planning in Pakistan. Washington: Population Council, The Evidence Project; 2015.

55 IRH. GREAT project endline report: Gender roles, equality and transformations project. Washington: IRH, Georgetown University; 2016.

56 Jewkes R, Nduna M, Levin J, Jama N, Dunkle K, Khuzwayo N, Koss M, Puren A, Wood K, Duvvury N. A cluster randomized-controlled trial to determine the effectiveness of Stepping Stones in preventing HIV infections and promoting safer sexual behaviour amongst youth in the rural Eastern Cape, South Africa: trial design, methods and baseline findings. Trop Med Int Health. 2006:11(1):3-16.

57 Jewkes R, Nduna M, Levin J, Jama N, Dunkle K, Puren A, Durvury N. Impact of stepping stones on incidence of HIV and HSV-2 and sexual behaviour in rural South Africa: cluster randomised controlled trial. Br Med J. 2008;337:a506.
58 Abramsky T, Devries K, Kiss L, Nakuti J, Kyegombe N, Starmann E, Cundill B, Francisco L, Kaye D, Musuya T, Michau L, Watts C. Findings from the SASA! Study: a cluster randomized controlled trial to assess the impact of a community mobilization intervention to prevent violence against women and reduce HIV risk in Kampala, Uganda. BMC Med. 2014;12(1):1-17.

59 Kyegombe N, Abramsky T, Devries KM, Starmann E, Michau L, Nakuti J, Musyua T, Heise L, Watts C. The impact of SASA! a community mobilization intervention on reported HIV-related risk behaviors and relationship dynamics in Kampala, Uganda. J Int AIDS Soc. 2014;17:19323.

60 CARE. The family planning results initiative in Kenya (2009 - 2012): Initial findings from the end line program evaluation. Atlanta: CARE; 2013.

61 Pulerwitz J, Barker G, Segundo M, Nascimento M. Promoting more genderequitable norms and behaviors among young men as an HIV/AIDS prevention strategy: Horizons program. Washington, DC: Population Council; 2006.

62 Ricardo C, Nascimento M, Fonseca V. Program H and Program M: Engaging young men and empowering young women to promote gender equality and health. Washington: Pan American Health Organization and Best Practices in Gender and Health; 2010.

63 Withers M, Dworkin SL, Onono M, Oyier B, Coher CR, Bukusi EA, Newmann SJ. Men's perspectives on their role in family planning in Nyanza Province, Kenya. Stud Fam Plann. 2015;46(2):201-15.

64 Hartmann M, Gilles K, Shattuck D, Kerner B, Guest G. Changes in couples' communication as a result of a male-involvement family planning intervention. J Health Comm. 2012;17(7):802-19.

65 Berer M. Men. Reprod Health Matters. 1996;7:7-10.

66 Piotrow PT, Kincaid DL, Hindin MJ, Lettenmaier CL, Kuseka I, Silberman T, Zinanga A, Chikara F, Adamchak DJ, Mbizvo MT, Lynn W, Mensah Kumah O, Kim YM. Changing men's attitudes and behavior: the Zimbabwe Male Motivation Project. Stud Fam Plann. 1992;23(6 Pt 1):365-75.

67 Kim YM, Marangwanda C. Stimulating men's support for long-term contraception: a campaign in Zimbabwe. J Health Comm. 1997;2:271-97.

68 United Nations Population Fund (UNFPA). Niger - Husbands' schools seek to get men actively involved in reproductive health. Niger: UNFPA; ND.

69 Stern E. Sexual health and rights. In: Edstrom J, Hassink A, Shahrokh T, Stern E, editors. Engendering men: A collaborative review of evidence on men and boys in social change and gender equality. Evidence report, Promundo-US, Sonke Gender Justice and the Institute of Development Studies. 2015. p. 74-115. http://niger.unfpa.org/SiteRep/ Ecole\%20des\%20maris.pdf. Accessed 17 Jan 2017.

70 Tao AR, Onono M, Baum S, Grossman D, Steinfeld R, Cohen CR. Providers' perspectives on male involvement in family planning in the context of a cluster-randomized controlled trial evaluating integrating family planning into HIV care in Nyanza Province, Kenya. AIDS Care. 2015;27(1):31-7.

71 Bietsch KE. Men's attitudes towards contraception in Sub-Saharan Africa. Afr J Reprod Health. 2015;19(3):41-54.

72 Nasar A, Hamid M, Bala A, and Brown E. Perceptions Among Married Men on the Use of Modern Contraceptive Methods in Sindh and Khyber Pakhtunkhwa (KPK) Provinces of Pakistan - Evidence from Participatory Ethnographic Evaluation Research (PEER). Abstract at the 2016 International Conference on Family Planning. Nusa Dua, Indonesia. 2016. https://www. xcdsystem.com/icfp/program/index.cfm?pgid=289\&search $=1 \&$ type $=$ speaker\&speakerid=175924\&submit=Go. Accessed 18 Dec 2016.

73 Agha S. Intentions to use contraceptives in Pakistan: implications for behavior change campaigns. BMC Public Health. 2010;10:450.

74 Barnett B, Eggleston E, Jackson J, Hardee K. Case study of the Women's Center of Jamaica Foundation program for adolescent mothers. Research Triangle Park: Family Health International; 1996.

75 Gayle H. Jamaican fathers and their sons: A tracer study of the babyfathers and sons of female participants of the Women's Centre Foundation of Jamaica in Westmoreland and St. Catherine, with a focus on father-son relationships and reproductive health. Kingston, Jamaica: University of the West Indies and Washington, DC: The Futures Group; 2002.

76 Haberland NA. The case for addressing gender and power in sexuality and HIV education: a comprehensive review of evaluation studies. Int Perspect Sex Reprod Health. 2015;41(1):31-42.

77 Greene M, Merrick T. The case for investing in research to increase access to and use of contraception among adolescents. Seattle: Alliance for Reproductive, Maternal and Newborn Health; 2015.

78 Sonke Gender Justice and Men EngageScorecard on sexual and reproductive health and rights (SRHR) policies in Africa: Engaging men and boys in the promotion of SRHR. Cape Town, South Africa; ND. 
79 Barker G, Greene M, Goldstein-Siegel E, Nascimento M, Márcio Segundo M, Ricardo C, Figueroa JG, Franzoni J, Redpath J, Morrell R, Jewkes R, Peacock D, Aguayo F, Sadler M, Das A, Singh SK, Pawar A. What men have to do with it: Public policies to promote gender equality. Washington: ICRW and Promundo; 2010.

80 Greene M, Walston N, Jorgensen A, Sambath MR, Hardee K. From adding to the burden to sharing the load: Guidelines for male involvement in reproductive health in Cambodia. Washington: Futures Group, POLICY Project; 2006.

81 Government of Ghana. Ghana family planning costed implementation plan (2016-2020). Accra, Ghana: Ghana Health Service, Government of Ghana; 2015.

82 Government of Malawi. Malawi costed implementation plan for family planning, 2016-2020. Lilongwe: Government of Malawi; 2015.

83 Ministry of Health, Uganda. 2014. Uganda costed implementation plan, 2015--2020. Kampala, Uganda: Ministry of Health; 2014.

84 Ministry of Health and Social Welfare (MOHSW) for the Republic of Senegal. National family planning action plan, 2012-2015. Dakar: MOHSW; 2012.

85 Ministry of Health and Social Welfare (MOHSW), United Republic of Tanzania. National costed implementation program. 2010-2015. Dar es Salaam: MOHSW; 2010.

86 Hassink A, Baringer L, Edstrom J, Sharokh T. Introduction: Framing the evidence and shifting gender norms. In: Edstrom J, Hassink A, Shahrokh T, Stern E, editors. Engendering men: A collaborative review of evidence on men and boys in social change and gender equality. Evidence report, EMERGE Evidence Review, Promundo-US, Sonke Gender Justice and the Institute of Development Studies. 2015. p. 10-23.

87 Greene ME and Barker G. Masculinity and its public health implications for sexual and reproductive health and HIV prevention." In: Sommer R and Parker M, editors. Routledge handbook of global public health. Routledge; 2010.

88 Institute for Reproductive Health (IRH. Promising practices for scale-up: A prospective case study of Standard Days Method ${ }^{\circledast}$ integration. Washington: The Institute for Reproductive Health, Georgetown University; 2013.

89 Kothari S. Using social media to promote family planning among Guatemalan men. WINGS. London: Unpublished Memo; 2016. Also see: https://www.facebook.com/183423425039015/photos/a.307242555990434. 65344.183423425039015/925820204132663/?type=3\&theater. Accessed 27 June 2016.

90 UNAIDS. World AIDS day 2015: On the fast-track to end AIDS by 2030, Focus on location and population. Geneva: UNAIDS; 2015.

91 Hosseini H, Naji H, Mashhadizadeh A, Rezaei A. Evaluation of men's participation in group training of their wives in family planning programs. Iran J Nurs Midwif Res. 2010;15 Suppl 1:292-5.

92 Yadav K, Singh B, Goswami K. Agreement and concordance regarding reproductive intentions and contraception between husbands and wives in rural Ballabgarh, India. Indian J Community Med. 2010;35(1):19-23.

93 Partnership for Maternal, Newborn and Child Health (PMNCH). Knowledge summary \#26: Engaging men and boys in RMNCH. PROMUNDO, UNFPA and $\mathrm{WHO} ; 2013$.

94 Levack, A, L Rolleri, and J DeAtley. Gen M, A gender-transformative teenage pregnancy prevention curriculum. NY: Engenderhealth; 2013.

95 Glasier A. Acceptability of contraception for men: a review. Contraception. 2010;82(5):453-6.

96 Heinemann K, Saad F, Wiesemes M, White S, Heinemann L. Attitudes toward male fertility control: results of a multinational survey on four continents. Human Reprod. 2005;20(2):549-56.

97 Dorman E, Bishai D. Demand for male contraception. Expert Rev Pharmacoecon Outcomes Res. 2012;12(5):605-13.

98 Glasier AF, Anakwe R, Everington D, Martin CW, van der Spuy Z, Cheng L, Ho PC, Anderson RA. Would women trust their partners to use a male pill? Human Reprod. 2000;5(3):646-9.

99 Olayinka CM, Okafor I and Odugbemi T. Are rural Nigerian men willing to accept new reversible male methods of family planning? A mixed method study in the Western Region. Abstract at the 2016 International Conference on Family Planning. Nusa Dua, Indonesia. 2016. https://www.xcdsystem. com/icfp/program/index.cfm?pgid=289\&search=1\&qtype= speaker\&speakerid=174824\&submit=Go. Accessed 19 Dec 2016.

100 Behre, HM, Zitzmann M, Anderson RA, Handelsman DJ, Lestari S W, McLachlan Rl, Meriggiola MC, Misro MM, Noe G, Wu FCW, Festin MPR, Habib NA, Vogelsong KM, Callahan MM, Linton KA and Colvard DS. Efficacy and safety of an injectable combination hormonal contraceptive for men. The Journal of Clinical Endochrinology and Metabolism. 2016;101(12) published online. http://dx.doi.org/10.1210/jc.2016-2141. Accessed 18 Dec 2016.

101 Devlin H. Male contraceptive jab almost as effective as female pill, trial shows. The Guardian. October 27 2016. https://www.theguardian.com/ society/2016/oct/27/male-contraceptive-jab-as-effective-as-female-pill-trialshows. Accessed 19 Dec 2016.

102 The Male Contraceptive Initiative. https://www.malecontraceptive.org/ prospective/. Accessed 19 Dec 2016.

\section{Submit your next manuscript to BioMed Central and we will help you at every step:}

- We accept pre-submission inquiries

- Our selector tool helps you to find the most relevant journal

- We provide round the clock customer support

- Convenient online submission

- Thorough peer review

- Inclusion in PubMed and all major indexing services

- Maximum visibility for your research

Submit your manuscript at www.biomedcentral.com/submit
C Biomed Central 